\title{
Study on value of ultrasonic elastography in diagnosis of clinical staging of cervical cancer and efficacy evaluation of radiotherapy
}

\author{
YINGYING ZHANG, YUANYUAN YAN and YUEJIE YANG \\ Department of Ultrasonic Medicine, Zhengzhou Central Hospital \\ Affiliated to Zhengzhou University, Zhengzhou, Henan 450000, P.R. China
}

Received November 8, 2018; Accepted March 7, 2019

DOI: $10.3892 / \mathrm{ol} .2019 .10190$

\begin{abstract}
The aim of this study was to investigate the application of ultrasonic elastography in the diagnosis of the clinical staging of cervical cancer (CC) and its evaluation value of the treatment effect of CC. A total of 160 suspected CC patients treated in our hospital from September 2016 to March 2018 were collected. Transvaginal conventional ultrasound and ultrasonic elastography were performed on patients to compare the results of the two in the diagnosis of the pathology and clinical staging of CC. Radiotherapy was used for patients confirmed as CC75 in 160 suspected CC patients. The value difference of strain ratio (SR) between conventional ultrasound and elastic ultrasound in the efficacy evaluation of CC patients was compared. The sensitivity (94.67\%), specificity (92.94\%) and diagnostic accordance rate $(93.75 \%)$ of ultrasonic elastography for $\mathrm{CC}$ were significantly higher than those of conventional ultrasound, with a statistically significant difference $(\mathrm{P}<0.001)$. The sensitivity and diagnostic accordance rate of ultrasonic elastography for the pathological diagnosis of $\mathrm{CC}$ in stage III and IV were significantly higher than those of conventional ultrasound, with a statistically significant difference $(\mathrm{P}<0.05)$. The sensitivity, specificity and diagnostic accordance rate of elastic ultrasound SR value in the efficacy evaluation of radiotherapy in $\mathrm{CC}$ patients were higher than those of conventional ultrasound. Except for the specificity, the other two P-values were $<0.05$, with a statistically significant difference. The elastography images of different stages of CC have some characteristic features. Ultrasonic elastography has a certain clinical value for the diagnosis and efficacy evaluation of $\mathrm{CC}$.
\end{abstract}

Correspondence to: Dr Yingying Zhang, Department of Ultrasonic Medicine, Zhengzhou Central Hospital Affiliated to Zhengzhou University, 195 Tongbai Road, Zhengzhou, Henan 450000, P.R. China E-mail: cew4s7@163.com

Key words: ultrasonic elastography, cervical cancer staging, cervical cancer pathology, diagnostic value, evaluation value

\section{Introduction}

The incidence of cervical cancer (CC) (1) ranks second among female malignant tumors worldwide. As one of the most common malignant tumors in gynecology, the most important risk factor for it (2) is the persistent infection of high-risk HPV that involves more than $89 \%$ of CC patients. Due to the high recurrence rate of high-risk HPV infection, CC patients in advanced stage have a poor prognosis with a high mortality. The early diagnosis and accurate analysis of $\mathrm{CC}$ are important for the treatment effect and prognosis of patients. At this stage, CC is diagnosed mainly by colposcopy, cervical and cervical tube biopsy, cervical cell scraping plate and highrisk HPV detection (3). Combined with the comprehensive clinical situation of CC patients, the clinical staging of CC was performed on them. The treatment methods and patient prognosis of different clinical stages of it are also different (4). With the continuous development and improvement of imaging technology in recent years, ultrasonic elastography technology has a good performance in the early diagnosis and pathological staging of $\mathrm{CC}$, with its non-invasive and repeatability favored by clinics and patients (5).

Ultrasonic elastography (6) is a new type of ultrasonic diagnostic technology. It uses the difference of elasticity coefficient between different biological tumor tissues or other lesion areas and surrounding normal tissues to generate difference in strain size. It also uses multi-color coding to display images, so as to determine the elasticity of lesion tissues, thereby analyzing the possibility of canceration. At present, ultrasonic elastography has been used in the clinical application of prostate cancer, thyroid cancer, breast cancer and early CC (7). In this study, ultrasonic elastography in the diagnosis of the clinical staging of $\mathrm{CC}$ and its evaluation value of the treatment effect of positive $\mathrm{CC}$ were investigated.

\section{Materials and methods}

Patient information. A total of 160 suspected CC patients treated in Zhengzhou Central Hospital Affiliated to Zhengzhou University (Zhengzhou, China) (pathologically examined and 75 patients diagnosed as CC) were included, aged 25-68 years old, with an average age of $50.7 \pm 8.4$ years (Table I). 
Inclusion and exclusion criteria. Only CC patients treated in Zhengzhou Central Hospital Affiliated to Zhengzhou University were included. The inclusion criteria of all CC patients were in line with the diagnostic criteria of international CC.

Patients with various family hereditary diseases were excluded and patients with cancer diseases other than $\mathrm{CC}$, were excluded.

This study was approved by the Ethics Committee of Zhengzhou Central Hospital Affiliated to Zhengzhou University. Patients who participated in this research had complete clinical data. The signed informed consents were obtained from the patients or the guardians.

Conventional vaginal ultrasound. The Hitachi Hi Vision 900 Color Doppler Ultrasound Diagnostic Apparatus (Hitachi, Ltd., Tokyo, Japan) was used. The patient was asked to drink $500 \mathrm{ml}$ of water and suppress the urine before examination, taking the supine position. Conventional abdominal gynecological ultrasound was performed before angiography. A conventional ultrasound diagnosis was performed after the general condition of the uterus and accessories recorded. After the rapid injection of ultrasonic contrast agent through the elbow vein, images from $120 \mathrm{sec}-3 \mathrm{~min}$ were continuously stored and observed. Ultrasonic image findings of the specific clinical staging of CC are shown in Table II.

Elastic ultrasound. The Hitachi Hi Vision 900 Color Doppler Ultrasound Diagnostic Apparatus (Hitachi, Ltd.) was used, equipped with tissue elastography software. A real-time elastography examination was performed after conventional vaginal ultrasound. The region of interest (ROI) of the CC patient's cancer mass was moved to the center of the image, so that the sampling frame size was more than twice the lesion size. The double-elastography mode was used for the simultaneous display of two-dimensional images and real-time elastography. The probe force was slowly controlled to pressurize to touch the cervix, with a pressure touch frequency of 2-4 times/sec. When the pressure curve was displayed, it was expressed as the comprehensive indicator of the pressure release frequency and pressure. At this time, the pressure touch frequency should be maintained between the comprehensive indicator of 3-4 levels, so as to maintain the stability between the pressure curve and the image for 5-6 sec. The change of the cancer tissue color in the sampling frame was observed. The elastography of the cancer site was obtained after the image was stable displayed. The average hardness of the tissue in the ROI was represented by green, that higher than the average hardness by blue, and that relatively low by red. The ultrasonic elastography of all CC patients was performed independently by three imaging physicians with more than 4 years of experience in elastic ultrasound.

Efficacy evaluation. Based on the World Health Organization (WHO) solid tumor clinical treatment evaluation criteria, the clinical efficacy of positive CC was divided into four parts. After treatment, the target lesion diameter increases by $\geq 50 \%$ compared with before treatment and new lesions are produced as progression of disease (PD). After treatment, the target lesion diameter is gradually reduced, with a reduction ratio
Table I. Clinical information sheet.

\begin{tabular}{lr}
\hline Factors & $\mathrm{n}(\%)$ \\
\hline Age & \\
$<50$ & $65(40.63)$ \\
$\geq 50$ & $95(59.37)$ \\
Married & \\
Yes & $143(89.38)$ \\
No & $17(10.62)$ \\
Pregnant & \\
Yes & $125(78.13)$ \\
No & $35(21.87)$ \\
Smoking & \\
Yes & $89(55.63)$ \\
No & $71(44.37)$ \\
FIGO staging of positive CC (n=75) \\
Stage I & \\
Stage II & $26(34.67)$ \\
Stage III & $14(18.67)$ \\
Stage IV & $19(25.33)$ \\
Pathological diagnosis typing & $16(21.33)$ \\
Squamous cell carcinoma & \\
Adenocarcinoma & $48(30.00)$ \\
Adenosquamous carcinoma & $67(41.87)$ \\
& $45(28.13)$ \\
\hline
\end{tabular}

of $>50 \%$ compared with before treatment, the duration is $>4$ weeks, and no new lesion is produced as partial remission (PR). After treatment, the target lesion diameter is gradually reduced, with a reduction ratio of $<50 \%$ compared with before treatment, and no new lesion is produced as stable disease (SD). The target lesion continues to disappear for $>4$ weeks and no new lesion is produced as complete remission (CR). Clinical overall efficiency $\mathrm{OR}=(\mathrm{CR}+\mathrm{PR}) /$ the total number of cases x $100 \%$.

Elastic ultrasound SR evaluation refers to relevant international reports on changes in the SR value of static ROI before and after CC radiotherapy. CR refers to patients with the disappearance of lesions after radiotherapy. PR refers to patients with the SR value decreasing to $81 \%$ before radiotherapy. SD refers to patients with the change in the SR value from 81 to $102 \%$ before treatment. PD refers to patients with the SR value increasing to more than $102 \%$ before radiotherapy. Overall efficiency of SR $\mathrm{OR}=(\mathrm{CR}+\mathrm{PR}) /$ the total number of cases $\mathrm{x} 100 \%$.

Statistical analysis. SPSS17.0 software (SPSS, Inc., Chicago, IL, USA) was used for statistical analysis. Count data were expressed as (\%). t-test was used for the comparison between the two methods. When the test results shows $\mathrm{P}<0.05$, there is a significant difference in the comparison between the two, and the difference is statistically significant.

\section{Results}

Comparison of results between conventional ultrasound and ultrasonic elastography in pathological diagnosis of CC. 
Table II. Ultrasonic image findings of different FIGO stages of CC.

Groups Image findings

Stage I

Stage II

Stage III

Stage IV
The cancer site is only in the cervix

The cancer site has gone beyond the cervix but not reached the lower third of the vagina or the pelvic wall The cancer site has invaded the pelvic wall or has spread to the lower third of the vagina

The cancer site has infiltrated the rectal mucosa or bladder, beyond the true pelvis
Table III. Results of conventional ultrasound in pathological diagnosis of CC.

\begin{tabular}{lccr}
\hline & \multicolumn{2}{c}{$\begin{array}{c}\text { Results of pathological } \\
\text { diagnosis }\end{array}$} \\
\cline { 2 - 3 } $\begin{array}{l}\text { Conventional } \\
\text { ultrasound }\end{array}$ & Positive & Negative & Total \\
\hline Positive & 54 & 25 & 79 \\
Negative & 21 & 60 & 81 \\
Total & 75 & 85 & 160 \\
\hline
\end{tabular}

Table IV. Results of ultrasonic elastography in pathological diagnosis of CC.

\begin{tabular}{lrrr}
\hline & \multicolumn{2}{c}{$\begin{array}{c}\text { Results of pathological } \\
\text { diagnosis }\end{array}$} \\
\cline { 2 - 3 } $\begin{array}{l}\text { Ultrasonic } \\
\text { elastography }\end{array}$ & Positive & Negative & Total \\
\hline Positive & 71 & 6 & 77 \\
Negative & 4 & 79 & 83 \\
Total & 75 & 85 & 160 \\
\hline
\end{tabular}

The results of conventional ultrasound in the diagnosis of 160 $\mathrm{CC}$ patients were: Among 75 positive $\mathrm{CC}$ patients diagnosed by pathology, 54 cases of positive $\mathrm{CC}$ were diagnosed by conventional ultrasound with a sensitivity of $72.00 \%(54 / 75)$, and 71 cases diagnosed by ultrasonic elastography with a sensitivity of $94.67 \%(71 / 75)$. The sensitivity of ultrasonic elastography was significantly higher than that of conventional ultrasound, with a statistically significant difference $(\mathrm{P}<0.001)$. Among 85 negative $\mathrm{CC}$ patients diagnosed by pathology, 60 cases were diagnosed by conventional ultrasound with a specificity of $70.59 \%$ (60/85), and 79 cases diagnosed by ultrasonic elastography with a specificity of $92.94 \%$ (79/85). The specificity of ultrasonic elastography was significantly higher than that of conventional ultrasound, with a statistically significant difference $(\mathrm{P}<0.001)$. The accordance rate of conventional ultrasound for the clinical diagnosis of CC was $71.25 \%$ (114/160), and that of ultrasonic elastography was $93.75 \%(150 / 160)$. The accordance rate of ultrasonic elastography was significantly higher than that of conventional ultrasound, with a statistically significant difference $(\mathrm{P}<0.001)$ (Tables III-V).
Comparison of results between conventional ultrasound and ultrasonic elastography in diagnosis of 75 cases of positive $C C$ in clinical stage III and IV. The sensitivity, specificity and diagnostic accordance rate of ultrasonic elastography in the pathological diagnosis of CC in stage III were 94.74, 96.43 and $96.00 \%$, respectively, higher than those of conventional ultrasound, which were 68.42,91.07 and 85.33\%, respectively. Except for the specificity, the other two P-values were $<0.05$, with a statistically significant difference. The sensitivity, specificity and diagnostic accordance rate in stage IV were 87.50, 98.31 and $96.00 \%$, respectively, higher than those of conventional ultrasound, which were $56.25,89.83$ and $82.66 \%$, respectively. Except for the specificity, the other two P-values were $<0.05$, with a statistically significant difference (Tables VI-X).

Comparison of evaluation value between conventional ultrasound and elastic ultrasound SR value in radiotherapy efficacy in CC patients. The sensitivity, specificity and diagnostic accordance rate of conventional ultrasound for the efficacy evaluation of radiotherapy in 75 positive $C C$ patients were $63.64,66.67$ and $64.00 \%$, respectively, lower than those of elastic ultrasound SR value, which were 86.36, 77.78 and $85.33 \%$, respectively. Except for the specificity, the other two P-values were $<0.05$, with a statistically significant difference (Tables XI-XIII).

\section{Discussion}

Cervical cancer (CC) is a female reproductive system malignancy caused by high-risk HPV, with an incidence second only to breast cancer (8) around the world. The onset symptom of early CC is not very obvious, leading to the development of it to the middle or late stage when visiting a doctor, which has a great impact on the treatment effect of CC. Therefore, CC patients should be early detected and early intervened. The reasonable treatment of them according to the different diagnosis results of different clinical stages of CC is important for their treatment efficacy and prognosis quality (9-11). At present, due to its long inspection time, cumbersome operation process and expensive price, the commonly used CC screening method (12-14) in clinic, such as traditional cervical pathological cell examination, has a certain impact on the patient's body and mind. The carcinogenesis of $\mathrm{CC}$ is from early to late stage, from stages I-IV, so pathological section diagnosis is not suitable for the examination of $\mathrm{CC}$ stages. In recent years, there has been a new breakthrough in ultrasonic imaging technology. It is found that the installation of unique elastic imaging software on the ultrasound scanner can greatly improve the accuracy rate of common ultrasound technology, so that the 
Table V. Comparison of results between conventional ultrasound and ultrasonic elastography in pathological diagnosis of CC.

\begin{tabular}{lcccr}
\hline Factors & Conventional ultrasound & Ultrasonic elastography & $\chi^{2}$ & P-value \\
\hline Sensitivity & $72.00 \%(54 / 75)$ & $94.67 \%(71 / 75)$ & 13.870 & $<0.001$ \\
Specificity & $70.59 \%(60 / 85)$ & $92.94 \%(79 / 85)$ & 14.240 & $<0.001$ \\
Diagnostic accordance rate & $71.25 \%(114 / 160)$ & $93.75 \%(150 / 160)$ & 28.050 & $<0.001$ \\
\hline
\end{tabular}

Table VI. Accuracy of conventional ultrasound in diagnosis of CC patients in stage III

\begin{tabular}{lccc}
\hline & \multicolumn{2}{c}{$\begin{array}{c}\text { Results of pathological } \\
\text { diagnosis }\end{array}$} & \\
\cline { 2 - 3 } $\begin{array}{l}\text { Conventional } \\
\text { ultrasound }\end{array}$ & Stage III & Non-stage III & Total \\
\hline Stage III & 13 & 5 & 18 \\
Non-stage III & 6 & 51 & 57 \\
Total & 19 & 56 & 75 \\
\hline
\end{tabular}

Table VII. Accuracy of conventional ultrasound in diagnosis of CC patients in stage IV.

\begin{tabular}{lccc}
\hline & \multicolumn{2}{c}{$\begin{array}{c}\text { Results of pathological } \\
\text { diagnosis }\end{array}$} & \\
\cline { 2 - 3 } $\begin{array}{l}\text { Conventional } \\
\text { ultrasound }\end{array}$ & Stage IV & Non-stage IV & Total \\
\hline Stage IV & 9 & 6 & 15 \\
Non-stage IV & 7 & 53 & 60 \\
Total & 16 & 59 & 75 \\
\hline
\end{tabular}

clinical application value is higher (15). In this study, the noninvasive ultrasonic elastography technology was used to detect and diagnose $\mathrm{CC}$ patients, and to explore its value in the efficacy evaluation of CC. The clinical diagnosis methods of CC are often cervical and cervical tube biopsy $(16,17)$. However, cervical biopsy has limitations in clearly showing the extent of $\mathrm{CC}$ violation, but elastic ultrasound can accurately show it, thus inferring the clinical staging of CC. CC staging has important clinical guiding significance for treatment options, surgical methods and the choice of radiotherapy or chemotherapy. The development of new imaging technology has improved the accordance rate of the clinical staging of CC (18).

In this study, the application of ultrasonic elastography technology in the clinical staging of CC was first explored. The result differences between conventional ultrasound and ultrasonic elastography in the pathological diagnosis of CC were compared. It was found that the sensitivity, specificity and diagnostic accordance rate of ultrasonic elastography for $\mathrm{CC}$ were significantly higher than those of conventional ultrasound, with a statistically significant difference $(\mathrm{P}<0.001)$. The sensitivity and diagnostic accordance rate of ultrasonic elastography in the pathological diagnosis of 75 cases of
Table VIII. Accuracy of ultrasonic elastography in diagnosis of CC patients in stage III.

\begin{tabular}{lccc}
\hline & \multicolumn{2}{c}{$\begin{array}{c}\text { Results of pathological } \\
\text { diagnosis }\end{array}$} \\
\cline { 2 - 3 } $\begin{array}{l}\text { Ultrasonic } \\
\text { elastography }\end{array}$ & Stage III & Non-stage III & Total \\
\hline Stage III & 18 & 2 & 20 \\
Non-stage III & 1 & 54 & 55 \\
Total & 19 & 56 & 75 \\
\hline
\end{tabular}

Table IX. Accuracy of ultrasonic elastography in diagnosis of CC patients in stage IV.

\begin{tabular}{lccc}
\hline & \multicolumn{2}{c}{$\begin{array}{c}\text { Results of pathological } \\
\text { diagnosis }\end{array}$} & \\
\cline { 2 - 3 } $\begin{array}{l}\text { Ultrasonic } \\
\text { elastography }\end{array}$ & Stage IV & Non-stage IV & Total \\
\hline Stage IV & 14 & 1 & 15 \\
Non-stage IV & 2 & 58 & 60 \\
Total & 16 & 59 & 75 \\
\hline
\end{tabular}

positive CC in stage III and IV were significantly higher than those of conventional ultrasound, with a statistically significant difference $(\mathrm{P}<0.05)$. Therefore, it is believed that ultrasonic elastography has a higher sensitivity, specificity and diagnostic accordance rate for the diagnosis of the clinical staging of CC. This is similar to the research viewpoints of Fischerova et al (19). They used the latest elastic ultrasound technology to determine the elastic strain ratio and elastic image pressure release indicator of CC patients and healthy control group, so as to diagnose the tumor staging and incidence of CC patients. The results showed that elastic ultrasound technology, which can be used as an effective diagnosis method of CC, had an extremely high diagnostic accordance rate for $\mathrm{CC}$ pathological patients. Its elastic strain ratio had a certain direct correlation with the onset degree of CC. After that, the value differences between conventional ultrasound and elastic ultrasound SR value in the efficacy of radiotherapy in positive CC patients were compared. The results showed that the sensitivity, specificity and diagnostic accordance rate of elastic ultrasound SR value in the efficacy evaluation of radiotherapy in positive $\mathrm{CC}$ patients were higher than those of conventional ultrasound. Except for the specificity, the other two P-values 
Table X. Comparison of results between conventional ultrasound and ultrasonic elastography in diagnosis of 75 cases of positive CC in clinical stage III and IV.

\begin{tabular}{lcrr}
\hline Factors & Conventional ultrasound & Ultrasonic elastography & $\chi^{2}$ \\
\hline Sensitivity & & & P-value \\
Stage III & $68.42 \%(13 / 19)$ & $94.74 \%(18 / 19)$ & 4.378 \\
Stage IV & $56.25 \%(9 / 16)$ & $87.50 \%(14 / 16)$ & 3.865 \\
Specificity & & & 0.036 \\
Stage III & $91.07 \%(51 / 56)$ & $96.43 \%(54 / 56)$ & 1.371 \\
Stage IV & $89.83 \%(53 / 59)$ & $98.31 \%(58 / 59)$ & 3.797 \\
Diagnostic accordance rate & & & 0.242 \\
Stage III & $85.33 \%(64 / 75)$ & $96.00 \%(72 / 75)$ & 5.050 \\
Stage IV & $82.66 \%(62 / 75)$ & $96.00 \%(72 / 75)$ & 0.025 \\
\hline
\end{tabular}

Table XI. Evaluation value of conventional ultrasound in radiotherapy efficacy in positive $\mathrm{CC}$ patients.

\begin{tabular}{lccc}
\hline & \multicolumn{2}{c}{$\begin{array}{c}\text { Evaluation of } \\
\text { radiotherapy efficacy }\end{array}$} & \\
\cline { 2 - 3 } $\begin{array}{l}\text { Conventional } \\
\text { ultrasound }\end{array}$ & $\begin{array}{l}\text { Effective } \\
(\mathrm{PR}+\mathrm{CR})\end{array}$ & $\begin{array}{c}\text { Ineffective } \\
\text { (SD+PD) }\end{array}$ & Total \\
\hline Effective & 42 & 3 & 45 \\
$\begin{array}{l}\text { Ineffective } \\
\text { Total }\end{array}$ & 24 & 6 & 30 \\
\hline
\end{tabular}

Table XII. Evaluation value of elastic ultrasound SR value in radiotherapy efficacy in positive $\mathrm{CC}$ patients.

\begin{tabular}{lccc}
\hline & \multicolumn{2}{c}{$\begin{array}{c}\text { Evaluation of } \\
\text { radiotherapy efficacy }\end{array}$} & \\
\cline { 2 - 3 } $\begin{array}{l}\text { Evaluation of elastic } \\
\text { ultrasound SR value }\end{array}$ & $\begin{array}{c}\text { Effective } \\
(\mathrm{PR}+\mathrm{CR})\end{array}$ & $\begin{array}{c}\text { Ineffective } \\
\text { (SD+PD) }\end{array}$ & Total \\
\hline Effective & 57 & 2 & 59 \\
Ineffective & 9 & 7 & 16 \\
Total & 66 & 9 & 75 \\
\hline
\end{tabular}

Table XIII. Comparison of value between conventional ultrasound and elastic ultrasound SR value in radiotherapy efficacy in positive CC patients.

\begin{tabular}{lccr}
\hline Factors & Conventional ultrasound & Ultrasonic elastography & $\chi^{2}$ \\
\hline Sensitivity & $63.64 \%(42 / 66)$ & $86.36 \%(57 / 66)$ & 9.091 \\
Specificity & $66.67 \%(6 / 9)$ & $77.78 \%(7 / 9)$ & 0.003 \\
Diagnostic accordance rate & $64.00 \%(48 / 75)$ & $85.33 \%(64 / 75)$ & 0.599 \\
\hline
\end{tabular}

were $<0.05$, with a statistically significant difference. In view of the application value of ultrasonic elastography in tumor efficacy, early researches (20) have confirmed that ultrasonic elastography technology and the clinical efficacy evaluation of tumor have a very high test consistency.

In this experiment, the number of CC cases collected was insufficient, with only 160 cases studied. It cannot be studied as big data, which may result in some contingency in experimental results. The image scanning instrument used this time was not the most advanced, causing some deviations in result analysis. Nevertheless, the error caused by all human factors was avoided as much as possible.

In summary, ultrasonic elastography has a very high application value in the diagnosis of the clinical staging of $\mathrm{CC}$ and in clinical efficacy evaluation. With non-invasive and high soft tissue resolution, clearly displaying the structure of various layers of the cervix, it can determine the lesion site, the extent of tumor infiltration into the vagina or uterus and the para-uterine metastasis, thereby improving the accuracy rate of clinical staging. In recent years, elastic ultrasound technology has been greatly developed (21), which can be widely promoted in clinic, so as to improve the diagnostic accuracy rate of the preoperative staging of $\mathrm{CC}$ and guide clinical treatment.

\section{Acknowledgements}

Not applicable.

\section{Funding}

No funding was received. 


\section{Availability of data and materials}

The datasets used and/or analyzed during the current study are available from the corresponding author on reasonable request.

\section{Authors' contributions}

YZ wrote the manuscript. YZ and YYang were responsible for conventional vaginal ultrasound data analysis. YYan and YYang contributed to elastic ultrasound data analysis. All authors read and approved the final manuscript.

\section{Ethics approval and consent to participate}

This study was approved by the Ethics Committee of Zhengzhou Central Hospital Affiliated to Zhengzhou University (Zhengzhou, China). Patients who participated in this research had complete clinical data. The signed informed consents were obtained from the patients or the guardians.

\section{Patient consent for publication}

Not applicable.

\section{Competing interests}

The authors declare that they have no competing interests.

\section{References}

1. Waggoner SE: Cervical cancer. Lancet 361: 2217-2225, 2003.

2. Sankaranarayanan R, Joshi S, Muwonge R, Esmy PO, Basu P, Prabhu P, Bhatla N, Nene BM, Shaw J, Poli URR, et al; Indian HPV vaccine study group: Can a single dose of human papillomavirus (HPV) vaccine prevent cervical cancer? Early findings from an Indian study. Vaccine 36: 4783-4791, 2018.

3. Liu Y, Zhang L, Zhao G, Che L, Zhang H and Fang J: The clinical research of Thinprep Cytology Test (TCT) combined with HPV-DNA detection in screening cervical cancer. Cell Mol Biol 63: 92-95, 2017.

4. Fuglsang K, Haldorsen IS, Avall-Lundqvist E, Lindahl G, Roed H, Woie K, Pakarinen P, Thoroddsen A, Anttila M and Blaakaer J: Cervical cancer staging, pretreatment planning, and surgical treatment in the Nordic countries-Survey from the Surgical Subcommittee of the Nordic Society of Gynecological Oncology. Acta Obstet Gynecol Scand 97: 1178-1184, 2018.

5. Csutak C, Badea R, Bolboaca SD, Ordeanu C, Nagy VM, Fekete Z, Chiorean L and Dudea SM: Multimodal endocavitary ultrasound versus MRI and clinical findings in pre- and posttreatment advanced cervical cancer. Preliminary report. Med Ultrason 18: 75-81, 2016

6. Cosgrove D, Piscaglia F, Bamber J, Bojunga J, Correas JM, Gilja OH, Klauser AS, Sporea I, Calliada F, Cantisani V, et al; EFSUMB: EFSUMB guidelines and recommendations on the clinical use of ultrasound elastography. Part 2: Clinical applications. Ultraschall Med 34: 238-253, 2013.

7. Zhi H, Xiao XY, Yang HY, Ou B, Wen YL and Luo BM: Ultrasonic elastography in breast cancer diagnosis: Strain ratio vs 5-point scale. Acad Radiol 17: 1227-1233, 2010.
8. Brodersen J: High incidence of cervical cancer in women over 60 is likely due to less intensive cervical screening in this generation of women. BMJ Evid Based Med 23: 37, 2018.

9. Wu ES, Jeronimo J and Feldman S: Barriers and challenges to treatment alternatives for early-stage cervical cancer in lowerresource settings. J Glob Oncol 3: 572-582, 2017.

10. Matsuo K, Shimada M, Yamaguchi S, Kanao H, Nakanishi T, Saito T, Kamiura S, Iwata T, Mikami M and Sugiyama T: Identifying a candidate population for ovarian conservation in young women with clinical stage IB-IIB cervical cancer. Int J Cancer 142: 1022-1032, 2018.

11. Santin AD, Zhan F, Bignotti E, Siegel ER, Cané S, Bellone S, Palmieri M, Anfossi S, Thomas M, Burnett A, et al: Gene expression profiles of primary HPV16- and HPV18-infected early stage cervical cancers and normal cervical epithelium: Identification of novel candidate molecular markers for cervical cancer diagnosis and therapy. Virology 331: 269-291, 2005.

12. Sangwa-Lugoma G, Mahmud S, Nasr SH, Liaras J, Kayembe PK, Tozin RR, Drouin P,Lorincz A, Ferenczy A and Franco EL: Visual inspection as a cervical cancer screening method in a primary health care setting in Africa. Int J Cancer 119: 1389-1395, 2006.

13. Zhao FH, Lewkowitz AK, Chen F, Lin MJ, Hu SY, Zhang X, Pan QJ, Ma JF, Niyazi M, Li CQ, et al: Pooled analysis of a selfsampling HPV DNA Test as a cervical cancer primary screening method. J Natl Cancer Inst 104: 178-188, 2012.

14. Zhu J, Norman I, Elfgren K, Gaberi V, Hagmar B, Hjerpe A and Andersson S: A comparison of liquid-based cytology and Pap smear as a screening method for cervical cancer. Oncol Rep 18: 157-160, 2007.

15. Huang WC, Yang JM, Yang YC and Yang SH: Ultrasonographic characteristics and cystoscopic correlates of bladder wall invasion by endophytic cervical cancer. Ultrasound Obstet Gynecol 27: 680-686, 2006.

16. Ma X, Li Q, Wang JL, Shao J, Zhu YC, Ding W, Zhang HS, Wang HY and Shen JK: Comparison of elastography based on transvaginal ultrasound and MRI in assessing parametrial invasion of cervical cancer. Clin Hemorheol Microcirc 66: 27-35, 2017.

17. Salvo G, Ramirez PT, Levenback CF, Munsell MF, Euscher ED, Soliman PT and Frumovitz M: Sensitivity and negative predictive value for sentinel lymph node biopsy in women with early-stage cervical cancer. Gynecol Oncol 145: 96-101, 2017.

18. Takagi H, Sakamoto J, Osaka Y, Shibata T, Fujita S and Sasagawa T: Usefulness of the maximum standardized uptake value for the diagnosis and staging of patients with cervical cancer undergoing positron emission tomography/computed tomography. Medicine (Baltimore) 97: e9856, 2018.

19. Fischerova D, Cibula D, Stenhova H, Vondrichova H, Calda P, Zikan M, Freitag P, Slama J, Dundr P and Belacek J: Transrectal ultrasound and magnetic resonance imaging in staging of early cervical cancer. Int J Gynecol Cancer 18: 766-772, 2008.

20. Lorenz A, Ermert H, Sommerfeld HJ, Garcia-Schürmann M, Senge T and Philippou S: Ultrasound elastography of the prostate. A new technique for tumor detection. Ultraschall Med 21: 8-15, 2000 (In German).

21. Sikdar S, Shah JP, Gebreab T, Yen RH, Gilliams E, Danoff J and Gerber LH: Novel applications of ultrasound technology to visualize and characterize myofascial trigger points and surrounding soft tissue. Arch Phys Med Rehabil 90: 1829-1838, 2009.

This work is licensed under a Creative Commons Attribution-NonCommercial-NoDerivatives 4.0 International (CC BY-NC-ND 4.0) License. 